\title{
Impact of simulator as a technology tool on problem solving skills of engineering students -a study report
}

\author{
Madhuri Mavinkurve' ${ }^{1}$, Mahesh Patil ${ }^{2}$ \\ ${ }^{1}$ Deapartment of Electronics and communications, \\ Thakur College of Engg and Technology, Kandivali, Mumbai \\ ${ }^{2}$ Department of Electrical Engineering, Indian Institute of Technology Bombay \\ 'mavinkurvemk@.gmail.com,2mbpatil@ee.iitb.ac.in
}

\begin{abstract}
Technology integration in education is one of theimportant approaches to develop higher order thinking skill among engineering students. In this study, we report the use of electronic circuit simulator SEQUEL to develop student's conceptual understanding. We applied SEQUEL in classroom environment to show students the effect of parameter variations on outputs of circuits. We conducted prepost single group study for two learning objectives such as (1) Draw output waveforms (LO1) (2) Predict output in given condition (LO2).We found that SEQUEL helped students to predict output for given conditions as number of students who scored high in post-test are more than pre-test for LO2.
\end{abstract}

Keywords: Technology integration, SEQUEL, LearningObjective,

\section{Madhuri Mavinkurve}

Deapartment of Electronics and communications, Thakur College of Engg and Technology, Kandivali, Mumbai mavinkurvemk@.gmail.

\section{Introduction}

One of the important objectives of engineering education is development of pan domain skills in addition to content. Pan domain thinking skills are beyond boundaries of discipline and applied across all the domains of engineering education. These skills are keys for transformative learning which is a need of 21 st century learning skills. These thinking skills are cognitive processes that human beings apply for sense-making and problem-solving (Beyer, 1988). Important thinking skills in engineering and science include system design thinking, algorithmic thinking, problem-posing, estimation, scientific modelling, problem solving, and so on.

Integration of technology in education is one of the important approaches to develop these transdisciplinary habits of mind (Mishra, Koehler and Henrikson, 2011). In recent years, the affordances of ICT have led to the development of technology which can promote various thinking skills such as those for modelling ability (Linn et. al. 2003), inquiry skills, (van Joolingen et. al., 2005), scientific argumentation (Scheuer et. al, 2010), and knowledge building (Scardamalia and Bereiter, 2014).

In engineering education, problem solving is one of the important skills and specified by ABET as important engineering graduate attribute (ABET, 2012). In the domain of electronics engineering, problem solving is related to circuit problem solving in which learners are expected to decode relevant 
information from given circuits or waveforms. They should be able to decide relevant formulae and encode the solution back into waveforms or appropriate outputs. A common problem faced by learners of electronic circuits is establishing a conceptual link between circuits and equations. Learners frequently are not able to predict system responses and make connections between equations and responses since these links are invisible to them (Ronen and Eliahu, 2000). Even though they are able to apply formulae for calculations, they cannot predict the desired outputs in case of changes in the parameters. In this study, we addressed this issue of developing circuit problem solving skill through technology integration in classroom environment.

We used SEQUEL, a simulator for circuit problem solving. SEQUEL is a versatile circuit simulation program (Patil, 2002), developed at IIT Bombay. It is particularly suitable for educational purposes since it can be freely downloaded and used by students and teachers in engineering colleges. SEQUEL helps learners to solve problems based on analog circuits. SEQUEL has a tool box to construct different circuits and simulations options to obtain various performance parameters of the circuit. SEQUEL allows simulation of analog circuits, digital circuits, and power electronic circuits. It employs implicit numerical integration methods commonly used in other circuit simulators such as SPICE, PSIM, etc. We applied SEQUEL in classroom to verify the results of change in parameters in problem solving.

\section{Related work}

Technology integration in teaching learning environments are broadly considered as any form of instruction where technologies are used to facilitate and enhance learning process (Goodyear and Retails, 2010). Technology based environments have been referred in various forms as tools and systems for understanding concepts, developing thinking skills and for effective communication and collaboration (Bruce and Levin, 1997; Jonassen, 2000; Conole and Dyke, 2004). Technology integration is mainlyconsidered as application of videos, animations, simulations etc. in classroom environment.

Computer based simulations are available for range of topics in science and engineering education (e.g. the PhET Sims at http://phet.colorado.edu, 2011; http://ocsar animations.iitb.ac.in). Simulations can be embedded into instructions to enhance student's conceptual understanding by promoting learning process (Rutten et.al, 2011). Simulations help learners to explore hypothetical situations, practice tasks and solve problems in realistic environment (van Berkum and de Jong, 1991). Learners can change variables and observe relevant changes in process or system performance which help them to develop conceptual understanding of topics (Windschitl and Andre, 1998). Simulative learning environments provide varying representations such as diagrams, waveforms, graphs (Blake and Scanlon, 2007). Ainsworth (2006) found that allowing learners to use multiple representations help to improve their conceptual understandings and dynamically linked multiple representations help to develop higher level cognitive skill among learners. Number of studies show that use of technology tools like simulations with traditional instructions has positive learning outcomes which improved conceptual understanding (Jimoyiannis and Komis, 2001; Stern, Barnea, and Shauli, 2008; McKagan, Handley, Perkins, and Wieman, 2009).

In engineering education for power electronics use of circuit simulation software helped to improve student's ability to comprehend behaviour of many power electronics circuits (Bauer et.al, 2005). Circuit simulation software enabled student to find out complicated power quantities which are otherwise difficult to obtain using analytical method. Interactive animation (Hart, 1993) for power electronics with self-assessment questions helped student to solve engineering problem and verify them. MATLAB along with its tool boxes and GUI facility proved as effective software package for teaching power electronics (Varadarajan and Valsan, 2005). This package helped students to explore behaviour of power electronics circuits. Overall literature review indicated that integration of simulations in traditional environments has positive impact on student's motivation, learning attitudes which resulted into improved learning gains. The simulative environments available for electronic circuits mostly provide self-learning environments for students. There are no studies reported for using simulator in classroom environment which will develop problem solving skills of students. Hence in this paper we develop classroom based application and evaluation of circuit simulator to develop problem solving skills of students.

We applied student's centric approach in which 
problem solutions are shown to students through simulated outputs and variations in the parameters are shown with corresponding changes in waveforms. We used SEQUEL as technology tool for integration in classroom environment. In next section we described the highlights of SEQUEL.

\section{SEQUEL as technology tool}

We consider examples of SEQUEL for an Electronics Circuits course, which is part of a fouryear undergraduate engineering programme in Mumbai University. Electronics Circuits is a fundamental subject and finds application in almost all streams of engineering. In order to solve circuit based problems students need to apply different concepts, principles and also may need to link various concepts. Thus solving circuit based problems with multiple concepts need appropriate construction of circuits as well as linkages of parameters to various graphs or characteristics. SEQUEL contains the toolbox which allows learners to construct as well as simulate circuits. It thus provides options for exploration through circuits. We investigated the use of SEQUEL to develop problem solving skill among students. A Graphical User Interface (GUI) incorporated in SEQUEL allows the users to enter their circuits in schematic form and view the simulation results as plots. The GUI has been designed to be "intuitive," and new users have been able to learn its use in a short time (about an hour) as observed in training programmes conducted at various engineering colleges in the past.

The SEQUEL component library includes all commonly used components in electronic circuits such as resistors, dependent and independent sources, inductors and capacitors, diodes, transistors, and transformers. A "model" option is also provided in which the user can create the model of a specific component (typically diodes and transistors). The model thus created can be saved and assigned to components in the user's circuit. For example, if there are four BJTs of type $\mathrm{BC} 107$ in the user's circuit, he/she can create the $\mathrm{BC} 107$ model and assign it to all four BJTs. SEQUEL can be used for DC simulation, $\mathrm{AC}$ (frequency-domain) simulation, and transient (time-domain) simulation. Digital circuits are handled using the event-driven approach (Raghuram, 1989). In addition, "steady-state waveform" (SSW) simulation is possible where the steady-state solution is directly computed, as opposed to going through a (possibly) long transient to reach the steady-state solution.

In order to use SEQUEL, the learner needs to apply the following steps:-

( Prepare the circuit schematic. In this step, the components involved in the circuit are placed in the canvas (i.e., the central window of the GUI, as shown in Fig. 1), they are wired as required, and component values (e.g., resistances and capacitances) are assigned.

口 Define the output variables. In this step, the user conveys to the simulator which variables (such as voltages and currents) are of interest in viewing the simulation results.

a Prepare the solve block(s). The purpose of a solve block is to indicate which type of simulation (DC, AC, transient) is desired and to assign the relevant parameters such as starting time and ending time.

口 Run simulation and view results. In this step, a circuit file is generated by the GUI and passed on to the SEQUEL program. After successful execution of the program, the variables specified by the user in the solve block(s) are made available for plotting.

Journal of Engineering Education Transformations, Volume , No, Month 2015, ISSN 2349-2473, eISSN 2394-1707

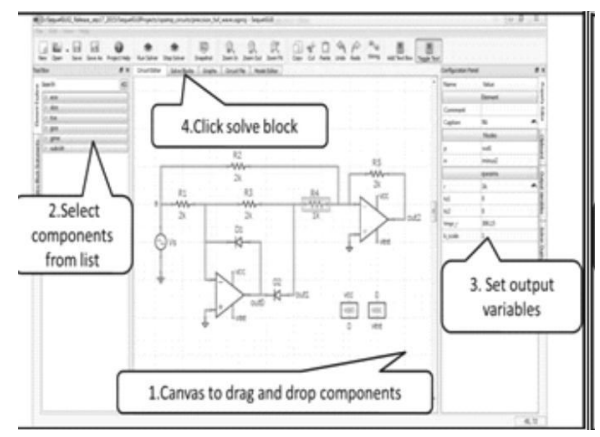

Fig. 1. SEQUEL GUI and application

The component values in an existing project (circuit) can be varied by the user by simply clicking on the concerned component and then using the "Property Editor" tab of the

Configuration Panel. After that, the user can run the simulation again and either view the new results in a separate graph window or superimpose them in a previous graph window. 


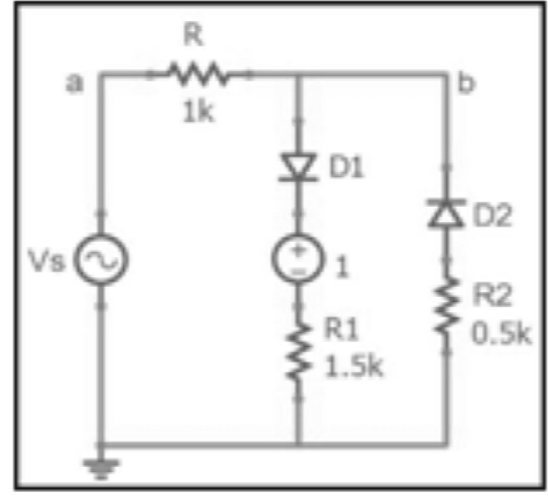

Fig. 2 Diode clipping circuits

The latter feature is useful when explaining how the operation of a circuit changes with respect to a specific component. A diode clipping circuit example is shown in Fig. 2, and the simulated transfer characteristics with output waveform are shown in Figs. 3 and 4, respectively. Students find difficulty in interpreting diode clipper circuit especially relating transfer characteristics with the output waveform. These types of simulations help to develop the linkages between different representations like graph and waveforms.

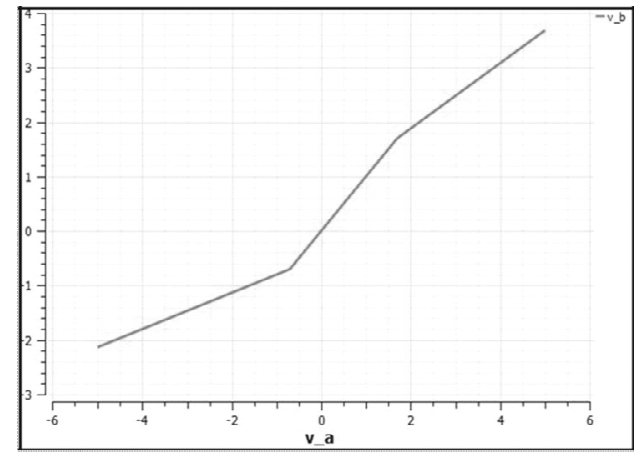

Fig. 3. Transfer characteristics simulated for diode circuit of fig 2

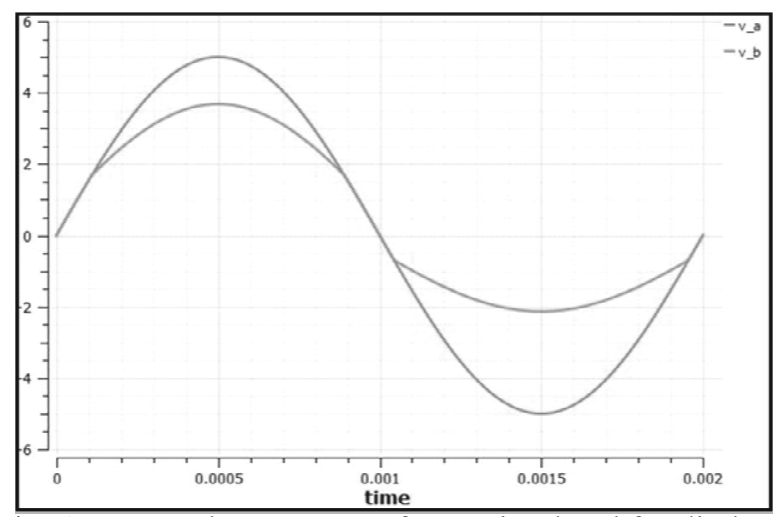

Fig. 4 Input and output waveforms simulated for diode circuit of Fig. 2

\section{Research study}

We developed learning material using SEQUEL to teach problem solving in the topic of 555 timers IC (Integrated Circuit) applications.555 timer IC is a versatile IC used to obtain various types of waveforms and test signals. We selected two major operating modes of 555 timer, viz., astable and monostable. We simulated 555 timer circuits with the help of internal diagrams of the IC (Fig. 5).

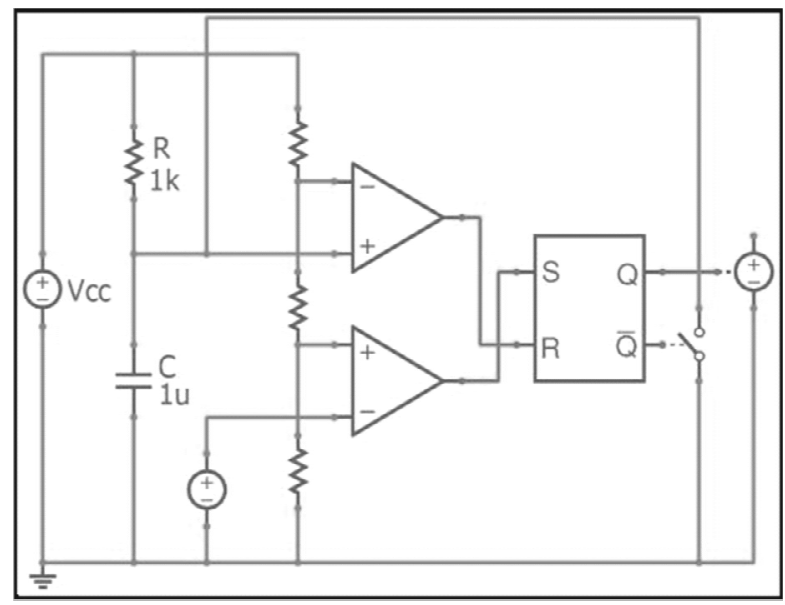

Fig. 5 Internal diagram of 555 monostable multivibrator

In both the applications, the output waveforms are dependent on the circuit components. We simulated the circuit and showed the output waveform with respect to the trigger applied to the Monostable Multivibrator (see Fig. 6). The output waveform is shown in Fig. 7.

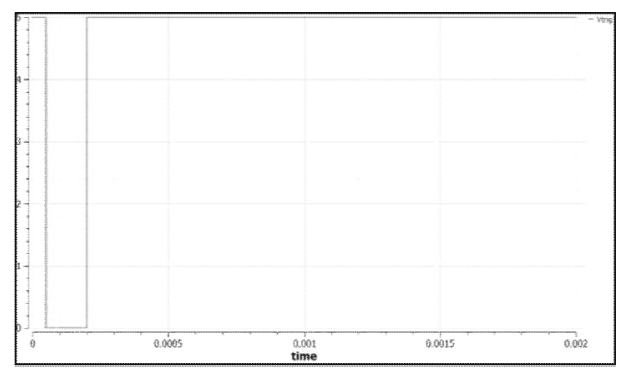

Fig. 6 Trigger input for $555 \mathrm{MMV}$

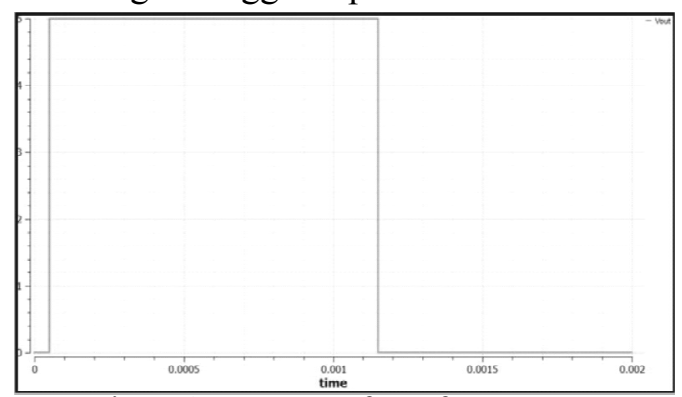

Fig. 7 Output waveform for 555 MMV 
We designed a similar circuit for astable operation and showed simulated outputs. We applied this material in classroom to support problem solving of students.

We studied the learning effectiveness of this instructional intervention through SEQUEL in classroom setting. The main research focus of our study was evaluation of impact of SEQUEL as a problem solving tool in classroom environment.

We decided Learning Objectives (LO) of our study to teach problem solving skill. Learning objectives are specific measurable outcomes of learners; we set following two learning objectives.

u LO1- Students will be able to draw output

waveforms for given circuit diagrams.

口 LO2- Students will be able to predict output waveforms for variation in circuit components.

Our research question was

RQ:-What is the difference between pre and post-test scores of students for circuit problem solving after SEQUELintervention?

In order to answer this research question we designed pre and post-test questions based on our three learning objectives.

Hypothesis of our study are

H1: Students post test scores for drawing waveforms (LO1) are higher than pre test scores after undergoing SEQUELintervention.

H2: Students post-test scores on prediction question (LO2) are higher than pre test scores after undergoing SEQUEL intervention.

Sample:-Students from third year engineering from Electronics and Telecommunication branch participated in

this study $(\mathrm{N}=32)$. Students were taught internal diagram of 555 timer circuits and its applications in traditional classroom environment. They were trained for routine problem solving which consists of formula application and calculation of different values. For this study, we conducted pre-test based on three problems. The first problem was a routine calculation problem while two other problems were based on learning objectives set by us. In both these problems, students need to decide type of outputs expected and choose a relevant formula and then solve the problem. Students were given 30 mins to solve all three problems. Once students completed the test, they were explained the solution through SEQUEL. For each problem, exact output waveforms were shown. SEQUEL was used to show changes in parameters with corresponding changes in the waveforms. The instructional intervention was given for $30 \mathrm{~min}$. Then students were given post-test for 30 min with similar type of problems with different applications.

Instrument: - Pre-test and post test questions were validated for content by two teachers (both authors) who are expert in the domain of analog electronics. We assessed solution script for attainment of learning objectives. We scored it using a 5-point scale. We interpreted each scale as follows 1-Concept, formula, interpretation and answer wrong 2-Concept, interpretation wrong but calculation is correct. 3Concept is right but interpretation is wrong. Calculations are correct.

4-Concept, interpretation correct but calculation wrong.

5-Everything applied correctly and answer is correct.

\section{Results and conclusions}

We compared the mean scores for pre and post-test as shown in table 1.

Table 1. Pre and post-test mean scores

\begin{tabular}{|l|l|l|l|l|}
\hline $\begin{array}{l}\text { Learning } \\
\text { objectives }\end{array}$ & $\begin{array}{l}\text { Pre-test } \\
\text { mean } \\
\text { score }\end{array}$ & $\begin{array}{l}\text { Post- } \\
\text { test } \\
\text { mean } \\
\text { score }\end{array}$ & t-value & p-value \\
\hline $\begin{array}{l}\text { LO1-Draw } \\
\text { waveform. }\end{array}$ & 4.3 & 4.6 & -1.38 & 0.17 \\
\hline $\begin{array}{l}\text { LO2- } \\
\text { Predict } \\
\text { output }\end{array}$ & 3.15 & 3.34 & -.38 & 0.7 \\
\hline
\end{tabular}

We found that even though the post-test scores for both learning objectives are high, there was no significant difference found in pre and post-test scores for attainment of $\mathrm{LO} 1$ and $\mathrm{LO} 2$.

We compared the pre-post score frequencies of $d$ 
find a way to use SEQUEL in a classroom setting to maximise the benefit of learning to develop higher order thinking skills.

\section{Acknowledgement}

We would like to thank Prof. Sahana Murthy, Indian Institute of Technology Bombay, for her guidance.

\section{References}

ABET Engineering Accreditation Commission. (2012). 2013-2014 Criteria for Accrediting Engineering Programs. ABET, Baltimore.

Ainsworth, S. (2006). DeFT: A conc van Joolingen, W. R., de Jong, T., Lazonder, A. W., Savelsbergh, E. R., and Manlove, S. (2005). Co-Lab: research and development of an online learning environment for collaborative scientific

discovery learning. Computers in human behavior, 21(4), 671-688.

Scardamalia. M. and Bereiter, C. (2014). Smart technology for self-organizing processes. Smart Learning Environments, 1(1). http://www.slejournal.com/content

/Scheuer, O., Loll, F., Pinkwart, N., and McLaren, B. M. (2010). Computer-supported argumentation: A review of the state of the art. International Journal of Computer-Supported Collaborative Learning, 5(1), 43-102.

ABET Engineering Accreditation Commission. (2012). 2013-2014 Criteria for Accrediting Engineering Programs. ABET, Baltimore.

Ainsworth, S. (2006). DeFT: A conceptual framework for considering learning with

Ronen, M., and Eliahu, M. (2000). Simulation-A bridge between theory and reality: The case of electric circuits. Journal of computer assisted learning, 16(1), 14-26.

Goodyear, P., and Retalis, S. (2010). Learning, technology and design.Technology-enhanced learning: design patterns and pattern languages, 2, 128.

Jonassen, D. H. (2000). Toward a design theory of problem solving .Educational technology research and development, 48(4), 63-85.

Conole, G., and Dyke, M. (2004). What are the affordances of information and communication technologies? Association for Learning Technology
Journal, 12(2), 113-124.

Bruce, B. C., and Levin, J. A. (1997). Educational technology: Media for inquiry, communication, construction, and expression. Journal of educational computing research, 17(1), 79-102.

Windschitl, M., and Andre, T. (1998). Using computer simulations to enhance conceptual change: the roles of constructivist instruction and student epistemological beliefs.

Journal of Research in Science Teaching, 35(2), 145160.

van Berkum, J. J. A., and de Jong, T. (1991). Instructional environments for simulations. Education and Computing, 6, 305-358.

Blake, C., and Scanlon, E. (2007). Reconsidering simulations in science education at a distance: features of effective use. Journal of Computer Assisted Learning, 23(6), 491-502.

Jimoyiannis, A., and Komis, V. (2001). Computer simulations in physics teaching and learning: a case study on students' understanding of trajectory motion. Computers and Education, 36(2), 183-204

Howland, J. L., Jonassen, D. H., and Marra, R. M. (2012). Meaningful learning with technology. Upper Saddle River, NJ: Pearson.

Stern, L., Barnea, N., and Shauli, S. (2008). The effect of a computerized simulation on middle school students' understanding of the kinetic molecular theory. Journal of Science Education and Technology, 17(4), 305-315.

McKagan, S. B., Handley, W., Perkins, K. K., and Wieman, C. E. (2009). A research-based curriculum for teaching the photoelectric effect. American Journal of Physics, 77(1), 87-94.

Bauer, P., Davat, B., Fedak, V., and Hajek, V. (2005, June). Educational visualization for teaching power electronics. In Power Electronics Education, 2005. IEEE Workshop (pp. 45-51). IEEE.

Varadarajan, M., and Valsan, S. P. (2005). MatPECSĐA MATLAB-based Power Electronic Circuit Simulation Package with GUI for Effective Classroom Teaching. Int. J. Engng Ed, 21(4), 606611.

Hart, D. W. (1993). Circuit simulation as an aid in teaching the principles of power electronics. Education, IEEE Transactions on, 36(1), 10-16. 
Friedman, A., and Kajder, S. (2006). Perceptions of beginning teacher education students regarding educational

technology. Journal of Computing in Teacher Education, 22(4), 147-151.

Mishra, P., Koehler, M. J., and Kereluik, K. (2009). The song remains the same: Looking back to the future of educational technology. Techtrends, 53(5), $48-5$

Gao, P., Choy, D., Wong, A. F. L., and Wu, J. (2009). Developing a better understanding of technologybased pedagogy. Australasian Journal of Educational Technology, 25(5), 714-730.

Lim, C. P. and Chai, C. S. (2008). Teachers' pedagogical beliefs and their planning and conduct of computer-mediated classroom lessons. British Journal of Educational Technology, 39(5), 807-828

Patil, M. B. (2002). A new public-domain program for mixed-signal simulation.Education, IEEE Transactions on, 45(2), 187-193.

Raghuram, R. (1989). Computer simulation of electronic circuits. New Age International.

Rutten, N., van Joolingen, W. R., and van der Veen, J. T. (2012). The learning effects of computer simulations in science education. Computers and Education,58(1), 136-153.

Bauer, P., Davat, B., Fedak, V., and Hajek, V. (2005, June). Educational visualization for teaching power electronics. In Power Electronics Education, 2005. IEEE Workshop (pp. 45-51).

Beyer, B. K. (1988) Developing a thinking skills program. Allyn and Bacon

Blake, C., and Scanlon, E. (2007). Reconsidering simulations in science education at a distance: features of effective use. Journal of Computer Assisted Learning, 23(6), 491-502.

Bruce, B. C., and Levin, J. A. (1997). Educational technology: Media for inquiry, communication, construction, and expression. Journal of educational computing research, 17(1), 79-102.

Conole, G., and Dyke, M. (2004). What are the affordances of information and communication technologies? Association for Learning Technology Journal, 12(2), 113-124.

Friedman, A., and Kajder, S. (2006). Perceptions of beginning teacher education students regarding educational technology. Journal of Computing in Teacher Education, 22(4), 147-151.
Gao, P., Choy, D., Wong, A. F. L., and Wu, J. (2009). Developing a better understanding of technologybased pedagogy. Australasian Journal of Educational Technology, 25(5), 714-730.

Goodyear, P., and Retalis, S. (2010). Learning, technology and design. Technology-enhanced learning: design patterns and pattern languages, 2, 128.

Hart, D. W. (1993). Circuit simulation as an aid in teaching the principles of power electronics. Education, IEEE Transactions on, 36(1), 10-16.

Journal of Engineering Education Transformations, Volume , No, Month 2015, ISSN 2349-2473, eISSN 2394-1707

Howland, J. L., Jonassen, D. H., and Marra, R. M. (2012). Meaningful learning with technology. Upper Saddle River, NJ: Pearson.

Jimoyiannis, A., and Komis, V. (2001). Computer simulations in physics teaching and learning: a case study on students' understanding of trajectory motion. Computers and Education, 36(2), 183-204

Jonassen, D. H. (2000). Toward a design theory of problem solving .Educational technology research and development, 48(4), 63-85.

Journal of Research in Science Teaching, 35(2), 145160.

Lim, C. P. and Chai, C. S. (2008). Teachers' pedagogical beliefs and their planning and conduct of computer-mediated classroom lessons. British Journal of Educational Technology, 39(5), 807-828

Linn, M. C., Clark, D., and Slotta, J. D. (2003). WISE design for knowledge integration. Science education, 87(4), 517-538.

McKagan, S. B., Handley, W., Perkins, K. K., and Wieman, C. E. (2009). A research-based curriculum for teaching the photoelectric effect. American Journal of Physics, 77(1), 87-94.

Mishra, P., Koehler, M. J., and Kereluik, K. (2009). The song remains the same: Looking back to the future of educational technology. Techtrends, 53(5), 48-5

Mishra, P., Koehler, M.J. and Henriksen, D. (2011). The Seven Trans-Disciplinary Habits of Mind: Extending the TPACK Framework Towards 21st Century learning. Educational Technology, 51(2), 2228.

Patil, M. B. (2002). Anew public-domain program for mixed-signal simulation.Education, IEEE 
Transactions on, 45(2), 187-193.

Raghuram, R. (1989). Computer simulation of electronic circuits. New Age International.

Ronen, M., and Eliahu, M. (2000). Simulation-A bridge between theory and reality: The case of electric circuits. Journal of computer assisted learning, 16(1), 14-26.

Rutten, N., van Joolingen, W. R., and van der Veen, J. T. (2012). The learning effects of computer simulations in science education. Computers and Education,58(1), 136-153.

Scardamalia. M. and Bereiter, C. (2014). Smart technology for self-organizing processes. Smart L e arning Environments, 1(1). http://www.slejournal.com/content

Scheuer, O., Loll, F., Pinkwart, N., and McLaren, B. M. (2010). Computer-supported argumentation: A review of the state of the art. International Journal of Computer-Supported Collaborative Learning, 5(1), 43-102.

Stern, L., Barnea, N., and Shauli, S. (2008). The effect of a computerized simulation on middle school students' understanding of the kinetic molecular theory. Journal of Science Education and Technology, 17(4), 305-315.

van Berkum, J. J. A., and de Jong, T. (1991). Instructional environments for simulations. Education and Computing, 6, 305-358.

van Joolingen, W. R., de Jong, T., Lazonder, A. W., Savelsbergh, E. R., and Manlove, S. (2005). Co-Lab: research and development of an online learning environment for collaborative scientific discovery

learning. Computers in human behavior, 21(4), 671688.

Varadarajan, M., and Valsan, S. P. (2005). MatPECSĐA MATLAB-based Power Electronic Circuit Simulation Package with GUI for Effective Classroom Teaching. Int. J. Engng Ed, 21(4), 606611.

Windschitl, M., and Andre, T. (1998). Using computer simulations to enhance conceptual change: the roles of constructivist instruction and student epistemological beliefs. 